\title{
Concession Period Decision Models for Public Infrastructure Projects Based on Option Games
}

\author{
Zhi Wang, ${ }^{1}$ Huan Tan, ${ }^{1}$ Jing Wang, ${ }^{1}$ and Chunyan $\mathrm{Hu}^{2}$ \\ ${ }^{1}$ Economics and Management School, Changsha University of Science and Technology, Hunan 410114, China \\ ${ }^{2}$ School of Public Administration, Central South University, Hunan 410082, China \\ Correspondence should be addressed to Chunyan Hu; mailtohcy@163.com
}

Received 13 May 2015; Accepted 27 August 2015

Academic Editor: Ruihua Liu

Copyright (c) 2015 Zhi Wang et al. This is an open access article distributed under the Creative Commons Attribution License, which permits unrestricted use, distribution, and reproduction in any medium, provided the original work is properly cited.

\begin{abstract}
Concession period is an important decision-making variable for the investment and construction of public infrastructure projects. However, we currently have few scientific methods to exactly determine the concession period. This paper managed to seek out concession period decision models for public infrastructure with option game theory, studied the influence of minimum government income guarantee and government investment on concession period, and demonstrated those models in the formulas mentioned in the paper. The research results showed that the increase of minimum government income guarantee value would shorten the concession period, while the increase of income volatility, that is, the uncertainty, would lengthen the concession period. In terms of government investment, optimal concession period would lengthen to some extent with the increase of government investment ratio and the income and the decrease of its guarantee value. Yet, optimal concession period would shorten in case of extreme highness of the government investment ratio due to its high guarantee value. And the government would accordingly shorten the concession period in case of the unchanged government investment ratio with the increased income volatility and risks. Still, the paper put forward the argument that the government would apply various guarantee methods and implement flexible concession period in accordance with the specific circumstances of public infrastructure projects.
\end{abstract}

\section{Introduction}

In recent years, the rapid growth of the investment and construction of infrastructure projects both at home and abroad has become an important way to promote economic growth and structural adjustment. The government, to solve the issue of shortage of funds for the purpose of projects construction, is adopting relatively flexible policies such as encouragement of nonpublic investment in the infrastructure projects to diversify the financing channels and patterns such as PPP and BOT. Therefore, to determine a rational concession period in the concession agreement is the key to effectively urge private investment in construction of infrastructure projects which are characterised by large-scale investment, long construction period, obvious social benefits, and multiple risks (Dai and Wen [1], Liu et al. [2]). Concession period is an important decision-making variable for the investment and construction of franchised infrastructure projects. Within the concession period, private investors are responsible for projects construction and operation and collect fees to settle the debts and make profits according to the agreed modes in concession negotiation. After the concession period, private investors will transfer the projects to the government for free or at the agreed price. Therefore, the length of the concession period will profoundly affect the interests of the private investors and the government.

Currently, there are two major categories of concession period decision-making methods for infrastructure projects: one is based on the net present value (NPV) of the project; for example, scholars like Li and Shen [3] established concession period decision model for the infrastructure BOT project from the perspective of income and cash flow. Scholars like Ye, Shen, Thomas, Song, and Huang [4-8], applying net present value (NPV) and Monte Carlo simulation method, analysed design issues on the project concession period. Qin [9] adopted CAPM model to change the discount rate value of the foregoing model into the risk-adjusted discount rate which is more suitable for deciding concession period of 
projects under system risks, while scholars including Wen [10-14] tried to confirm the risk income ratio of the projects on the basis of investors' risk appetite. Nevertheless, such method failed to considerate the uncertainty of the projects' future profits, the long operating period, and the influence of government guarantee and ignored the flexibility and complexity of determining the concession period under the market environment.

The second is based on game theory and real options theory. The concession period's decision of infrastructure project can be seen as a game between the investors and the government. In the process of bargaining, investors, at the price of harming the interests of the government and the public, will manage to prolong the concession period which lay a solid foundation for the construction quality of infrastructure. On the contrary, the government will try to shorten the concession period to safeguard the interests of the government and the public, and the shortened concession period will definitely damage the quality and operating life of infrastructure construction and increase the maintenance costs after retaking the project. In model PPP, Medda [15] regarded the interests allocation between the government and private investors as a bargaining game and analyzed the strategic behaviour and potential moral risks in case guarantee value is higher than finance loss. Scholars like Yang et al. [16] established concession period decision model by analysing the game features between the government and the project corporation. Gao et al. [17] adopted the "cakesharing" model in complete information dynamic game to study how to determine BOT project concession period with relatively stable profits and known life cycle of project. Scholars like Shen et al. [18], after considering the bargaining behaviour between the government and nongovernment in the concession period negotiations, established a complete information dynamic game model to determine the concession period and explained the effect of negotiation interaction factors on confirming concession period from the angle of the negotiation. Applying game theory, Bao [19] established a dynamic game and the concession period decision model with changed investment cost. Wu et al. [20] established the game model for project corporation's investment and government's concession period and analysed the issues about the optimal strategies, respectively, with Stackelberg's game method. Zhang and Durango-Cohen [21] built a game model for concession negotiation between government and private investors and studied how the government encourages private investment in the projects by offering some preferential policies. These results laid the foundation for solving issues about concession period decision but failed to solve the problems on determining the concession period flexibly. As an option, real option bears more flexibility for the decision making of government and project corporation [22]. Gao et al. [23] pointed out that infrastructure BOT project, differing form general projects, has specific risk guarantee which is provided by the government for the purpose of attracting nongovernmental investment and it can be seen as down-and-in options. As for PPP projects, government will participate in investments and bear the risks. Scholars like Takashima et al. [24] explored the investment decisions of the government and private investors based on PPP model, applied real options method to analyze the ratio of shared investment costs and risks in project operation, and pointed out that the size of shared ratio will affect investment decisions and the value of the project. Cruz and Marques [25], taking hospital project as an example, considered the uncertainty of PPP projects as an opportunity and built a model based on real options theory to assess the benefits from flexibility of the contract and concluded that the uncertainty increased the project value.

Public infrastructure investment and financing process involves many people's interests and each has different focus on economic efficiency and social benefits. On determining the concession period of the projects, we will take the game process between the investors and the government into consideration except for the uncertainties. And the option game theory integrating real option theory with game theory explains the impact of option game characteristics on concession period under the uncertain conditions of minimum government income guarantee and government participation in the risk sharing in a better way. Smets [26] was the first to introduce the game theory to real options analysis framework. Based on this, Ottoo [27] pointed out that the government may divide BOT infrastructure projects into several phases and give the right to invest in nextphase project construction to companies which successfully won the bidding of phase I. This option can be regarded as growth option, that is, the option to grasp the growth opportunity. Scholars like Alonso-Conde et al. [28], taking financing structure and contract clauses in the PPP model as a real option, analyzed how these options affect the investment incentives, and the government transfers the project benefits to the private investors via government guarantee. Articles in China analysing the project concession period decisionmaking problems with option game method are few and far between. Using the option game, Guo et al. [29] studied issues about construction costs of infrastructure BOT project phase II and its concession period determination as well but failed to consider the value and effect of government guarantees. Gong et al. [30] used the real options approach and game theory and built the quantitative decision negotiation model for concession period of BOT projects with the minimum government income guarantees but did not consider the impact of other government guarantees on the concession period. In reality, the government will take various measures to attract nongovernmental investors to participate in investment of public infrastructure construction, such as offering investors the minimum income guarantee, or investing and sharing the risks. Different guarantee forms will exert different effects on concession period. Our paper contributions are as follows: beginning with projects without government guarantees, taking the elements such as minimum government income guarantee and government investment and sharing risks into consideration, building concession period decision models for public infrastructure projects with option game theory, studying the influence of different government guarantees on concession period, and determining government guarantee forms and concession period rationally. 
TABLE 1: Complete information about bargaining game elements between two parties.

\begin{tabular}{lcc}
\hline Participants & Investors & The government \\
\hline $\begin{array}{l}\text { The strategic space } \\
\text { Payoff function }\end{array}$ & $\left(0, T_{x}\right)$ & $\left(T_{x}, T\right)$ \\
\hline
\end{tabular}

This paper consists of 6 sections as follows. We propose basic assumption to build the models in Section 2. We establish option game decision model for the concession period of the projects without government guarantee and determine the optimal concession period under these circumstances which serves as a reference for the following analysis in Section 3. In Section 4, we establish the option game decision model for the concession period of the projects with government guarantee after considering the minimum government income guarantee and government investment and sharing risks and attain the analytical solutions to the optimal concession period. In Section 5, in order to make the analysis more intuitive and clear, we explain the optimal concession period obtained from option game decision model for the project concession period in Section 3 and Section 4 by numerical examples analysis and we make a summary of the conclusion in Section 6.

\section{Model Hypotheses}

Since concession negotiation comes after bid evaluation, the information is open. In order to facilitate analysis, we assume that the government and investors share the relevant information in the bid, face common project conditions, and know clearly about each other's strategies and that the other party knows theirs; both parties are inclined to pursue appetite for neutral risk and maximum benefit. Investors and the government will weigh the advantages and disadvantages in the bargaining on determining the project concession period.

We assume that the concession period negotiation is the complete information bargaining game between the two parties. Game has three elements of participants, the strategic space and payoff function; in the process of negotiation, the three elements are shown in Table 1.

Among them, $E$ is expectations, $T$ is the project's planning use life, $T_{x}$ is the concession period, $I$ is initial investment cost, $V$ is the value of the project, $V_{t}$ is instantaneous net cash flow, and $G$ is government guarantee value. We assume that $V_{t}$ follows geometric Brownian motion, so it satisfies the random process as follows: $d V_{t}=\alpha V_{t} d t+\sigma V_{t} d z$. $\alpha$ is the expected growth rate of $V_{t}, \sigma$ is the volatility of $d V_{t} / V_{t}$, and $d z$ is increment of standard wiener process.

In the concession negotiation stage, investors have submitted the tender, so the first round of the game is to offer price by the investors. Government may accept it or reject it: if government accepts the tender, the game ends, and the concession period is determined; if the government rejects the tender, then the game enters into the second round, and the role of two sides changes, continuing bargaining over and over again. After selecting qualified candidates through bidding, the government, according to the quality of the scheme, determines the optimal investors to negotiate and will negotiate with the next candidate in case of failure. As a dominant role in the negotiations, the government has the say in accepting or rejecting the agreement in the final phase. Overall, concession period negotiations are the bargaining game for even times of the price offered by the investors in the first round. Through backward induction, we can get the following negotiations equalization payment of investors:

$$
\begin{aligned}
V_{I}^{E}(R) & =E\left(\int_{0}^{T} V_{t} e^{-u t} d t-I\right)\left(1-\delta+\delta^{2}-\cdots \delta^{R-1}\right) \\
& =\left[\frac{V_{0}\left(1-e^{-m T}\right)}{m}-I\right]\left(\frac{1-\delta^{R}}{1+\delta}\right),
\end{aligned}
$$

where $E(V)$ is the total income within project life, $R$ is the number of negotiating rounds, $\delta$ is the discount rate of negotiation round, $V_{0}$ as the initial income flow, $u>\alpha$ is the risk-adjusted discount rate for future income, and $m=u-$ $\alpha>0$ is convenience income of a project. When negotiating rounds tend to be infinite, Shaked and Sutton's [31] and Cui et al's [32] research results show that the subgame refining Nash equilibrium of the game equals the investors' balance payment in the first round:

$$
V_{I}^{1}(R)=\frac{E(V)}{1+\delta}=\left[\frac{V_{0}\left(1-e^{-m T}\right)}{m}-I\right]\left(\frac{1}{1+\delta}\right) .
$$

In the negotiation process between government and investors, the government will determine the concession period $T_{x}$ in favour of the interests of the public, and $T_{x}$ will meet the following decision model:

$$
\begin{array}{ll}
\max _{T_{x}} & E\left[V_{\left(T_{x}, T\right)}-E(G)\right] \\
\text { s.t. } & E\left[V_{\left(0, T_{x}\right)}-I+E(G)\right] \geq \bar{u} .
\end{array}
$$

Formula (3) is utility function of the government, that is, concession period under the maximum public interests. Formula (4) is the restricted conditions for government utility function, namely, the maximum expected utility the investors get from the project during the concession period. Among them, $\bar{u}$ stands for opportunity utility, that is, the maximum expected utility the investors get from other projects while being lost in the infrastructure projects.

After the government determines the concession period $T_{x}$, investors take the initial investment cost $I$ as decisionmaking variables will meet the following decision model in the case of profit guarantee:

$$
\max _{I} E\left[V\left(0, T_{x}\right)-I+E(G)\right]
$$

Formula (5) shows the cost invested by investors in the project construction in the pursuit of maximum profit after the concession period determined by the government. 


\section{The Option Game Model between Investors without Government Guarantees and Government}

$G=0$ in the case of no government guarantee; then, the income function in concession period investors without government guarantees is

$$
E\left[V_{\left(0, T_{x}\right)}-I+E(G)\right]=\frac{V_{0}\left(1-e^{-m T_{x}}\right)}{m}-I .
$$

Then, during the period of time, that is, from the government to recover project management rights, to the end of the project period, the expected function of government revenue is:

$$
E\left[V_{\left(T_{x}, T\right)}-E(G)\right]=\frac{V_{0}\left(e^{-m T_{x}}-e^{-m T}\right)}{m} .
$$

According to the respective decision models of governments and investors and using backward induction, we get investors' construction costs $I$ under the conditions of the assumed concession period, and the government determines the appropriate concession period value $T_{x}$ accordingly. Thus, the government and investors reach a win-win situation by taking the interests of both sides into account.

Substituting (7) into (3) and (6) into (4), we can obtain the government's decision-making models and restricted conditions:

$$
\begin{array}{ll}
\max _{T_{x}} & \frac{V_{0}\left(e^{-m T_{x}}-e^{-m T}\right)}{m} \\
\text { s.t. } & \frac{V_{0}\left(1-e^{-m T_{x}}\right)}{m}-I \geq \bar{u} .
\end{array}
$$

Lagrange multiplier method can be used to solve the maximization of formula (8). Let $\lambda$ be a Lagrange multiplier, (8) combine together to form a Lagrangian function, we can know

$$
\begin{aligned}
L\left(T_{x}, \lambda\right)= & \frac{V_{0}\left(e^{-m T_{x}}-e^{-m T}\right)}{m} \\
& +\lambda\left[\frac{V_{0}\left(1-e^{-m T_{x}}\right)}{m}-I-\bar{u}\right] .
\end{aligned}
$$

Seeking first-order partial derivatives of $T_{x}$ and $\lambda$ in formula (9), respectively, we can know

$$
\begin{aligned}
\frac{\partial L}{\partial T_{x}} & =(\lambda-1) V_{0} e^{-m T_{x}}=0 \\
\frac{\partial L}{\partial \lambda} & =\frac{V_{0}\left(1-e^{-m T_{x}}\right)}{m}-I-\bar{u}=0 .
\end{aligned}
$$

We can know from (11) that

$$
T_{x}=\frac{\ln V_{0}-\ln \left[V_{0}-m(I+\bar{u})\right]}{m} .
$$

\section{The Option Game Models between Investors with Government Guarantees and Government}

Government guarantees aim to attract investors (domestic and foreign consortiums, companies, and individuals) to invest in the construction of infrastructure projects and are government commitments to share the various risks such as investment return, franchising operation, and environmental conditions in the investment process. Generally, such guarantees have a variety of forms, such as the minimum income guarantee of project, franchising operation price guarantee, legal consistency guarantees, and risk sharing.

4.1. The Impact of Minimum Government Income Guarantee on the Concession Period. Assuming that government provides investors with a minimum income guarantee $\underline{V}$, that is to say, the guaranteed value is 0 when the income is not less than $\underline{V}$ and the guaranteed value is $\underline{V}-V_{\left(0, T_{x}\right)}$ when the income is less than $\underline{V}$, then the guaranteed value $G=$ $\max \left[0, \underline{V}-V_{\left(0, T_{x}\right)}\right]$ is equivalent to a European put option with $V_{\left(0, T_{x}\right)}$ as the underlying asset, $\underline{V}$ as exercise price, and $T_{x}$ as expiry date. According to real options approach, we can obtain the expected value of government guarantees with B-S option equation:

$$
\begin{aligned}
E(G) & =\underline{V} e^{-r T_{x}} N\left(-d_{2}\right)-\frac{V_{0}\left(1-e^{-m T_{x}}\right)}{m} N\left(-d_{1}\right) \\
& \geq 0 .
\end{aligned}
$$

Among them, $r$ is risk-free income rate and $N(\cdot)$ is the accumulation normal distribution function.

Similarly, we can obtain the expected income function of the investors with government guarantee within the period of the concession:

$$
\begin{aligned}
E[ & \left.V\left(0, T_{x}\right)-I+E(G)\right] \\
& =\frac{V_{0}\left(1-e^{-m T_{x}}\right)}{m}-I+E(G) .
\end{aligned}
$$

Then, the expected income function from the date when the government took over the operation right to the end of planned use life is

$$
E\left[V\left(T_{x}, T\right)-E(G)\right]=\frac{V_{0}\left(e^{-m T_{x}}-e^{-m T}\right)}{m}-E(G) .
$$

Substituting (15) in (3) and (14) in (4), we can obtain the government's decision-making model and its constraints under the premise of a minimum income guarantee:

$$
\begin{aligned}
\max _{T_{x}} & \frac{V_{0}\left(e^{-m T_{x}}-e^{-m T}\right)}{m}-E(G) \\
\text { s.t. } & \frac{V_{0}\left(1-e^{-m T_{x}}\right)}{m}+E(G)-I \geq \bar{u} .
\end{aligned}
$$


Lagrange multiplier method can be used to solve the maximization of formula (16). Let $\lambda$ be a Lagrange multiplier, (16) combine together to form a Lagrangian function, we can know

$$
\begin{aligned}
L\left(T_{x}, \lambda\right)= & \frac{V_{0}\left(e^{-m T_{x}}-e^{-m T}\right)}{m}-E(G) \\
& +\lambda\left[\frac{V_{0}\left(1-e^{-m T_{x}}\right)}{m}+E(G)-I-\bar{u}\right] .
\end{aligned}
$$

Substituting formula (13) into (17), we can obtain

$$
\begin{aligned}
& L\left(T_{x}, \lambda\right)=\frac{V_{0}\left(e^{-m T_{x}}-e^{-m T}\right)}{m}-\underline{V} e^{-r T_{x}} N\left(-d_{2}\right) \\
& +E\left[V_{\left(0, T_{x}\right)}\right] N\left(-d_{1}\right)+\lambda\left[\frac{V_{0}\left(1-e^{-m T_{x}}\right)}{m}\right. \\
& \left.+\underline{V} e^{-r T_{x}} N\left(-d_{2}\right)-E\left[V_{\left(0, T_{x}\right)}\right] N\left(-d_{1}\right)-I-\bar{u}\right] .
\end{aligned}
$$

Seeking first-order partial derivatives of $T_{x}$ and $\lambda$ in formula (18), respectively, we can know

$$
\begin{aligned}
\frac{\partial L}{\partial T_{x}} & =\left[V_{0} e^{-m T_{x}}-r \underline{V} e^{-r T_{x}} N\left(-d_{2}\right)\right. \\
- & \left.V_{0} e^{-m T_{x}} N\left(-d_{1}\right)\right](\lambda-1)=0 \\
\frac{\partial L}{\partial \lambda} & =\frac{V_{0}\left(1-e^{-m T_{x}}\right)}{m} N\left(d_{1}\right)+\underline{V} e^{-r T_{x}} N\left(-d_{2}\right)-I \\
- & \bar{u}=0 .
\end{aligned}
$$

And we will work out the numerical solution to $T_{x}$ and $\lambda$ in (19) and (20).

\subsection{The Impact on Concession Period of Government Partici-} pation in Risk Sharing. Guarantee provided by government participating in risk sharing means that the government allocates some funds into the construction of infrastructure projects. Suppose government's investment amount is $G$, accounting for $\theta$ of the total investment $I$, that is, $G=\theta I(0<$ $\theta<1$ ), income sharing ratio is also $\theta$, that is, the government guaranteed value is 0 when $\theta$ is zero, and the guaranteed value is $\theta\left(I-V_{\left(0, T_{x}\right)}\right)$ when $0<\theta<1$, and the guaranteed value $G=\operatorname{Max}\left[0, \theta\left(I-V_{\left(0, T_{x}\right)}\right)\right]$ is therefore equivalent to a European put option with $V_{\left(0, T_{x}\right)}$ as underlying asset, $\theta I$ as exercise price, and $T_{x}$ as expiry date. According to real options approach, we can obtain the expected value of government guarantees with B-S option equation:

$$
\begin{aligned}
E(G) & =\theta I e^{-r T_{x}} N\left(-d_{2}\right)-\frac{V_{0}\left(1-e^{-m T_{x}}\right)}{m} N\left(-d_{1}\right) \\
& \geq 0 .
\end{aligned}
$$

Among them, $r$ is risk-free income rate and $N(\cdot)$ is the accumulation normal distribution function.

Similarly, we can obtain the expected income function of the investors with government within the period of the concession:

$$
\begin{aligned}
E & {\left[(1-\theta) V\left(0, T_{x}\right)-(1-\theta) I+E(G)\right] } \\
& =(1-\theta) \frac{V_{0}\left(1-e^{-m T_{x}}\right)}{m}-(1-\theta) I+E(G) .
\end{aligned}
$$

Then, the expected income function of the government within the planned use life is

$$
\begin{aligned}
E[ & \left.V\left(T_{x}, T\right)+\theta V\left(0, T_{x}\right)-\theta I-E(G)\right] \\
= & \frac{V_{0}\left(e^{-m T_{x}}-e^{-m T}\right)}{m}+\theta \frac{V_{0}\left(1-e^{-m T_{x}}\right)}{m}-\theta I \\
& -E(G) .
\end{aligned}
$$

In the negotiation process between government and investors, the government will determine the concession period $T_{x}$ in favour of the interests of the public and $T_{x}$ will meet the following decision model:

$$
\begin{array}{cl}
\max _{T_{x}} & E\left[V\left(T_{x}, T\right)+\theta V\left(0, T_{x}\right)-\theta I-E(G)\right] \\
\text { s.t. } & E\left[(1-\theta) V\left(0, T_{x}\right)-(1-\theta) I+E(G)\right] \geq \bar{u} .
\end{array}
$$

Lagrange multiplier method can be used to solve the maximization of formula (23) and (24). Let $\lambda$ be a Lagrange multiplier, and using (23) and (24) combined together to form a Lagrangian function, we can know

$$
\begin{aligned}
& L\left(T_{x}, \lambda\right)=\frac{V_{0}\left(e^{-m T_{x}}-e^{-m T}\right)}{m}+\theta \frac{V_{0}\left(1-e^{-m T_{x}}\right)}{m} \\
& -\theta I-E(G)+\lambda\left[(1-\theta) \frac{V_{0}\left(1-e^{-m T_{x}}\right)}{m}\right. \\
& -(1-\theta) I+E(G)-\bar{u}] .
\end{aligned}
$$

Substituting (21) into (22),

$$
\begin{aligned}
& L\left(T_{x}, \lambda\right)=\frac{V_{0}\left(e^{-m T_{x}}-e^{-m T}\right)}{m}+\theta \frac{V_{0}\left(1-e^{-m T_{x}}\right)}{m} \\
& \quad-\theta I-\theta I e^{-r T_{x}} N\left(-d_{2}\right)+\frac{V_{0}\left(1-e^{-m T_{x}}\right)}{m} N\left(-d_{1}\right) \\
& +\lambda\left[(1-\theta) \frac{V_{0}\left(1-e^{-m T_{x}}\right)}{m}-(1-\theta) I\right. \\
& \left.+\theta I e^{-r T_{x}} N\left(-d_{2}\right)-\frac{V_{0}\left(1-e^{-m T_{x}}\right)}{m} N\left(-d_{1}\right)-\bar{u}\right] .
\end{aligned}
$$


TABLE 2: The relationship between $T_{x}, E(G)$, and $\sigma$.

\begin{tabular}{lccccccccccc}
\hline$T_{x}$ & $\sigma=0$ & $\sigma=0.1$ & $\sigma=0.2$ & $\sigma=0.3$ & $\sigma=0.4$ & $\sigma=0.5$ & $\sigma=0.6$ & $\sigma=0.7$ & $\sigma=0.8$ & $\sigma=0.9$ & $\sigma=1$ \\
\hline$E(G)=0$ & 12 & - & - & - & - & - & - & - & - & - & - \\
$E(G)=1 * 10^{8}$ & 12 & 17 & 32 & 58 & 76 & 84 & 87 & 87 & 88 & 88 & 88 \\
$E(G)=2 * 10^{8}$ & 12 & 15 & 25 & 45 & 61 & 69 & 72 & 73 & 74 & 74 \\
$E(G)=3 * 10^{8}$ & 12 & 14 & 22 & 37 & 52 & 60 & 64 & 65 & 66 & 66 \\
$E(G)=4 * 10^{8}$ & 11 & 13 & 19 & 32 & 46 & 54 & 58 & 59 & 60 & 60 \\
$E(G)=5 * 10^{8}$ & 11 & 13 & 18 & 29 & 41 & 49 & 53 & 55 & 55 & 55 \\
$E(G)=6 * 10^{8}$ & 11 & 12 & 17 & 26 & 37 & 45 & 49 & 51 & 51 & 52 \\
$E(G)=7 * 10^{8}$ & 11 & 12 & 15 & 23 & 34 & 42 & 46 & 48 & 48 & 49 \\
$E(G)=8 * 10^{8}$ & 11 & 11 & 15 & 21 & 31 & 39 & 43 & 45 & 46 & 46 \\
$E(G)=9 * 10^{8}$ & 11 & 11 & 14 & 20 & 29 & 36 & 40 & 42 & 43 & 43 \\
$E(G)=10 * 10^{8}$ & 10 & 11 & 13 & 18 & 26 & 34 & 38 & 40 & 41 & 41 & 42 \\
\hline
\end{tabular}

Seeking first-order partial derivatives of $T_{x}$ and $\lambda$ in formula (27), respectively, we can know

$$
\begin{aligned}
& \frac{\partial L}{\partial T_{x}}=(\lambda-1)\left[(1-\theta) V_{0} e^{-m T_{x}}-r \theta I e^{-r T_{x}} N\left(-d_{2}\right)\right. \\
& \left.\quad+V_{0} e^{-m T_{x}} N\left(-d_{1}\right)\right]=0 \\
& \frac{\partial L}{\partial \lambda}=(1-\theta) \frac{V_{0}\left(1-e^{-m T_{x}}\right)}{m}-(1-\theta) I \\
& \quad+\theta I e^{-r T_{x}} N\left(-d_{2}\right)-\frac{V_{0}\left(1-e^{-m T_{x}}\right)}{m} N\left(-d_{1}\right)-\bar{u} \\
& \quad=0 .
\end{aligned}
$$

And we will work out the numerical solution to $T_{x}$ and $\lambda$ in (28) and (29).

\section{Numerical Examples}

We will make further analysis with numerical examples to get more intuitive and clear result. Comparison results of multiple sets of data simulation show that the analysis results of this paper are not sensitive to the selection of parameter values, and the specific size of parameter value selected in the models within practical scope does not affect analysis conclusions of this paper. Therefore, this paper makes simulation analysis by selecting a set of data which best suits the actual economic situation as a basic data. Assuming that the initial investment cost of an infrastructure project $I$ is 6 billion, and $V_{0}$, the initial income, is 400 million, then the convenience income of the project is $2 \%$ and the risk-free interest rate of financial asset pricing is computed from the average interest rates of interbank market, interbank bond repo market, and exchange repo market and so is the riskfree income rate, and we take the comparatively long retaking period of the project into account and assume that $r$ is 5\% [29], $\underline{V}$, the minimum income guarantee, is eight billion, and $\bar{u}$, the opportunity utility, is 3 billion.

Firstly, substituting the relevant data into formula (12), we can obtain concession period of projects without government guarantees $T_{x}=29.8919$ years. That is to say, the initial

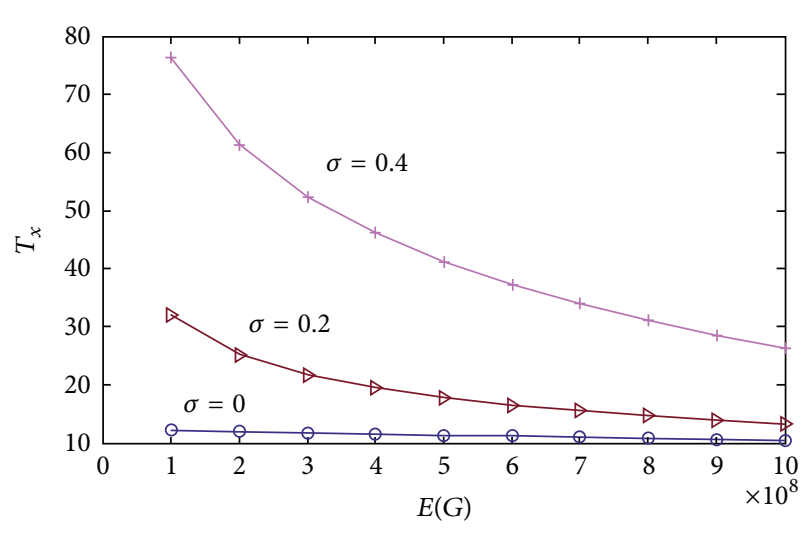

Figure 1: $\sigma=0,0.2,0.4$, the relationship between $E(G)$ and $T_{x}$.

investment cost of the investors is 6 billion, the initial income is 400 million, the convenience income is 0.02 , and the opportunity utility is 3 billion. The government's optimal decision is to transfer the operation right of the infrastructure projects to investors with the concession period of 30 years which conforms to the concession operation period of most of the public infrastructure projects with concession operation right (such as highways, urban sewage treatment plants, and power plants) in China.

Secondly, using relevant data, we conduct numerical simulation of formula (19) with MATLAB; the result is shown in Figure 1 and Table 2. Figure 1 shows the relationship between the expected value of minimum government income guarantee $E(G)$ and the concession period $\left(T_{x}\right)$ when the curves from the bottom to the top represent the income volatility $0,0.2$, and 0.4 , respectively. We can get from Figure 1 and Table 2, under certain income volatility, that the concession period gradually shortens with the increase of expected values of the minimum income guarantee; that is to say, the increase of the government guarantee will shorten the optimal concession period, and while expected values of the minimum income guarantee are fixed, the concession period will lengthen with the increase of income volatility; that is, the uncertainties will lengthen the optimal concession period. Simultaneously, Table 2 shows that when the expected 
TABLE 3: The relationship between $T_{x}, \theta$, and $\sigma$.

\begin{tabular}{lccccccccccc}
\hline$T_{x}$ & $\sigma=0$ & $\sigma=0.1$ & $\sigma=0.2$ & $\sigma=0.3$ & $\sigma=0.4$ & $\sigma=0.5$ & $\sigma=0.6$ & $\sigma=0.7$ & $\sigma=0.8$ & $\sigma=0.9$ & $\sigma=1$ \\
\hline$\theta=0$ & 30 & 30 & 30 & 31 & 31 & 31 & 30 & 30 & 30 & 30 & 30 \\
$\theta=0.1$ & 31 & 31 & 32 & 32 & 32 & 32 & 31 & 31 & 31 & 31 & 31 \\
$\theta=0.2$ & 33 & 33 & 34 & 34 & 34 & 33 & 33 & 32 & 32 & 32 \\
$\theta=0.3$ & 36 & 36 & 36 & 36 & 36 & 35 & 35 & 34 & 34 & 34 \\
$\theta=0.4$ & 40 & 40 & 40 & 40 & 39 & 38 & 38 & 37 & 37 & 37 \\
$\theta=0.5$ & 46 & 46 & 46 & 46 & 45 & 43 & 42 & 42 & 42 & 41 \\
$\theta=0.6$ & 56 & 56 & 56 & 56 & 54 & 53 & 52 & 52 & 51 & 51 & 51 \\
$\theta=0.7$ & 80 & 80 & 80 & 80 & 79 & 78 & 77 & 77 & 77 & 77 & 77 \\
$\theta=0.8$ & 1 & 1 & 1 & 1 & 1 & 1 & 1 & 1 & 1 & 1 \\
$\theta=0.9$ & 3 & 3 & 3 & 3 & 3 & 3 & 3 & 3 & 4 & 5 \\
$\theta=1.0$ & 5 & 5 & 5 & 5 & 5 & 5 & 6 & 7 & 9 & 1 \\
\hline
\end{tabular}

TABLE 4: The relationship between $E(G), \theta$, and $\sigma$.

\begin{tabular}{lccccccccccc}
\hline$E(G)\left(10^{8}\right)$ & $\sigma=0.0$ & $\sigma=0.1$ & $\sigma=0.2$ & $\sigma=0.3$ & $\sigma=0.4$ & $\sigma=0.5$ & $\sigma=0.6$ & $\sigma=0.7$ & $\sigma=0.8$ & $\sigma=0.9$ & $\sigma=1.0$ \\
\hline$\theta=0$ & - & - & - & - & - & - & - & - & - & - & - \\
$\theta=0.1$ & - & - & - & - & - & - & 0.02 & 0.53 & 0.88 & 1.08 & 1.20 \\
$\theta=0.2$ & - & - & - & - & - & 0.32 & 1.07 & 1.64 & 2.01 & 2.23 & 2.34 \\
$\theta=0.3$ & - & - & - & - & 0.23 & 1.13 & 1.95 & 2.55 & 2.94 & 3.15 & 3.26 \\
$\theta=0.4$ & - & - & - & - & 0.75 & 1.73 & 2.57 & 3.17 & 3.53 & 3.73 & 3.82 \\
$\theta=0.5$ & - & - & - & 0.21 & 1.02 & 1.98 & 2.76 & 3.29 & 3.58 & 3.72 & 3.78 \\
$\theta=0.6$ & - & - & - & 0.26 & 0.94 & 1.68 & 2.23 & 2.56 & 2.71 & 2.77 & 2.79 \\
$\theta=0.7$ & - & - & - & 0.12 & 0.41 & 0.67 & 0.82 & 0.88 & 0.90 & 0.90 & 0.90 \\
$\theta=0.8$ & 41.11 & 41.11 & 41.11 & 41.11 & 41.11 & 41.11 & 41.11 & 41.11 & 41.12 & 41.13 & 41.10 \\
$\theta=0.9$ & 34.86 & 34.86 & 34.86 & 34.81 & 34.81 & 34.82 & 34.74 & 34.68 & 34.51 & 34.25 & 33.84 \\
$\theta=1.0$ & 30.00 & 30.00 & 29.99 & 30.01 & 30.00 & 30.00 & 29.99 & 29.99 & 30.01 & 30.01 & 30.00 \\
\hline
\end{tabular}

value of minimum government income guarantee is relatively low, $E(G)$ varies within 0-100 million Yuan. Only when volatility rate is relatively low, government will attract the private investment by prolonging concession period. On the contrary, if the volatility rate is relatively high, the extension of the concession period is difficult to have attraction to private investors.

Thirdly, using relevant data, we conduct numerical simulation of formula (29) with MATLAB; the results are shown in Figure 2 and Table 3. When $\theta$ varies within the range of $0-$ 0.7 , the concession period gradually extends with the increase of government investment ratio under fixed income volatility. But when $\theta$ further increases, the concession period rapidly declines. That shows that the optimal concession period, with the government investment ratio within certain scope $(\theta=0-$ 0.7 ), will extend with the increase of government investment ration and income and the decrease of its guarantee value under fixed income volatility. But optimal concession period will be shortened by the government accordingly in case of extreme highness of the government investment $(\theta>0.7)$ ratio, that is, regarding the guarantee value of government investment as put option, for the high guarantee value, which is verified in Table 4. And concession period will accordingly shorten with fixed government investment ratio and increased income volatility. That fact shows that the government will accordingly shorten the concession period

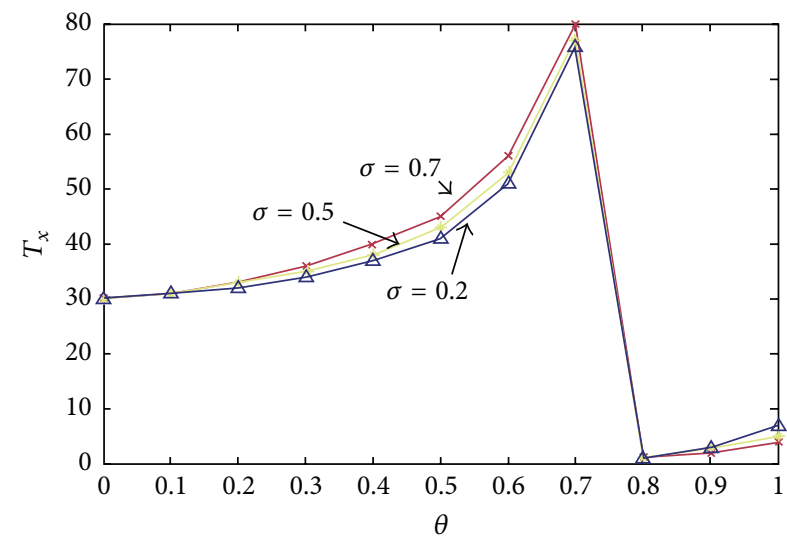

FIGURE 2: $\sigma=0.2,0.5,0.7$, the relationship between $T_{x}$ and $\theta$.

in case of the unchanged government guarantee with the increased income volatility and risks.

\section{Conclusions}

This paper, taking the elements such as minimum government income guarantee and government investment and sharing risks into consideration, established concession 
period decision models for public infrastructure with option game theory, studied the influence of minimum government income guarantee and government investment on concession period, and verified the fact that the increase of minimum government income guarantee value will shorten the concession period, while the increase of income volatility, that is, the uncertainty, will lengthen the concession period with numerical simulation. In terms of government investment, optimal concession period will lengthen to some extent with the increase of government investment ratio and the income and the decrease of its guarantee value. Yet, optimal concession period will shorten in case of extreme highness of the government investment ratio due to its high guarantee value. And the government will accordingly shorten the concession period in case of the unchanged government investment ratio with the increased income volatility and risks.

The above conclusions show that the government, in accordance with the specific circumstances of the public infrastructure projects and various guarantee modes [33], will implement flexible concession period system which will be written in the Concession Period Agreement: the concession period ends after the investors regain their investment and get the stipulated income and will not be restricted to a fixed period, hence reaching the goal to encourage private investors to participate in the construction of public infrastructure and balance the interest between investors and the public as well.

\section{Conflict of Interests}

The authors declare that there is no conflict of interests regarding the publication of this paper.

\section{Acknowledgments}

This work was supported in part by the National Social Science Foundation of China (Grant no. 10CGL063), National Natural Science Foundation of China (no. 71303262), Program of Research Center of Modern Enterprise Management of Hunan Province (Grant no. 1ljqkf07), and the Collaborative Innovation Center of Services and Urbanization of Hunan and Key Project of the Education Department of Hunan Province (no. 14A008).

\section{References}

[1] Z. Dai and F. Wen, "Robust CVaR-based portfolio optimization under a genal affine data perturbation uncertainty set," Journal of Computational Analysis \& Applications, vol. 16, no. 1, pp. 93103, 2014.

[2] J. Liu, M. Tao, C. Ma, and F. Wen, "Utility indifference pricing of convertible bonds," International Journal of Information Technology \& Decision Making, vol. 13, no. 2, pp. 429-444, 2013.

[3] Q. Li and L. Shen, "Concession period decision model for infrastructure BOT projects," Journal of Management Engineering, vol. 14, no. 1, pp. 43-46, 2000 (Chinese).

[4] S. Ye and R. L. K. Tiong, "The effect of concession period design on completion risk management of BOT projects," Construction Management and Economics, vol. 21, no. 5, pp. 471-482, 2003.
[5] L. Y. Shen and Y. Z. Wu, "Risk concession model for build/ operate/transfer contract projects," Journal of Construction Engineering and Management, vol. 131, no. 2, pp. 211-220, 2005.

[6] S. Thomas Ng, J. Xie, Y. K. Cheung, and M. Jefferies, "A simulation model for optimizing the concession period of public-private partnerships schemes," International Journal of Project Management, vol. 25, no. 8, pp. 791-798, 2007.

[7] J. Song, D. Song, and C. Tan, "Decision model for concession period of power generation with wastes BOT projects," China Management Science, no. 10, pp. 86-93, 2013 (Chinese).

[8] C. Huang, H. Kuang, X. Chen, and F. Wen, "An LMI approach for dynamics of switched cellular neural networks with mixed delays," Abstract and Applied Analysis, vol. 2013, Article ID 870486, 8 pages, 2013.

[9] X. Qin, "Calculation models for concession period of BOT project based on CAPM," Journal of Management Engineering, no. 2, pp. 60-63, 2005 (Chinese).

[10] F. Wen and X. Yang, "Skewness of return distribution and coefficient of risk premium," Journal of Systems Science and Complexity, vol. 22, no. 3, pp. 360-371, 2009.

[11] F. Wen, Z. He, and X. Chen, "Investors' risk preference characteristics and conditional skewness," Mathematical Problems in Engineering, vol. 2014, Article ID 814965, 14 pages, 2014.

[12] F. Wen, Z. He, X. Gong, and A. Liu, "Investors' risk preference characteristics based on different reference point," Discrete Dynamics in Nature and Society, vol. 2014, Article ID 158386, 9 pages, 2014.

[13] F. Wen, Z. He, Z. Dai, and X. Yang, "Characteristics of investors' risk preference for stock markets," Economic Computation and Economic Cybernetics Studies and Research, vol. 48, no. 3, pp. 235-254, 2014.

[14] F. Wen, X. Gong, Y. Chao, and X. Chen, "The effects of prior outcomes on risky choice: evidence from the stock market," Mathematical Problems in Engineering, vol. 2014, Article ID 272518, 8 pages, 2014.

[15] F. Medda, "A game theory approach for the allocation of risks in transport public private partnerships," International Journal of Project Management, vol. 25, no. 3, pp. 213-218, 2007.

[16] H. W. Yang, J. Zhou, and J. M. He, "The concession period decision model of the traffic BOT based on game theory," Journal of Management Engineering, vol. 17, no. 3, pp. 93-95, 2003 (Chinese).

[17] L. F. Gao, G. J. Zhang, and Y. Du, "BOT projects concession period determination with 'cake-sharing' model in dynamic game," Business Research, no. 2, pp. 24-26, 2006 (Chinese).

[18] L. Y. Shen, H. J. Bao, Y. Z. Wu, and W. S. Lu, "Using bargaininggame theory for negotiating concession period for BOT-type contract," Journal of Construction Engineering and Management, vol. 133, no. 5, pp. 385-392, 2007.

[19] H. J. Bao, "Dynamic game for concession period decision of infrastructure BOT projects," Journal of Management Engineering, vol. 23, no. 4, pp. 139-147, 2009 (Chinese).

[20] X. L. Wu, J. Zhou, and W. Hong, "Decision model for concession period of infrastructure BOT within effective operation period," Journal of System Engineering, vol. 26, no. 3, pp. 373-378, 2011 (Chinese).

[21] Z. A. Zhang and P. L. Durango-Cohen, "A strategic model of public-private partnerships in transportation: effect of taxes and cost structure on investment viability," Research in Transportation Economics, vol. 36, no. 1, pp. 9-18, 2012. 
[22] C. Huang, C. Peng, X. Chen, and F. Wen, "Dynamics analysis of a class of delayed economic model," Abstract and Applied Analysis, vol. 2013, Article ID 962738, 12 pages, 2013.

[23] F. Gao, J. Guo, and Q. B. Zhao, "Government guarantee value on infrastructure projects based on barrier option," Prediction, no. 2, pp. 76-80, 2007 (Chinese).

[24] R. Takashima, K. Yagi, and H. Takamori, "Government guarantees and risk sharing in public-private partnerships," Review of Financial Economics, vol. 19, no. 2, pp. 78-83, 2010.

[25] C. O. Cruz and R. C. Marques, "Flexible contracts to cope with uncertainty in public-private partnerships," International Journal of Project Management, vol. 31, no. 3, pp. 473-483, 2013.

[26] F. Smets, "Exporting versus FDI: the effect of uncertainty, irreversibilities and strategic interactions," Working Paper, Yale University, New Haven, Conn, USA, 1991.

[27] R. E. Ottoo, "Valuation of internal growth opportunities: the case of a biotechnology company," Quarterly Review of Economics and Finance, vol. 38, no. 3, part 2, pp. 615-633, 1998.

[28] A. B. Alonso-Conde, C. Brown, and J. Rojo-Suarez, "Public private partnerships: incentives, risk transfer and real options," Review of Financial Economics, vol. 16, no. 4, pp. 335-349, 2007.

[29] M. L. Guo, Y. Yang, and W. X. Hu, "Decision model for concession period of infrastructure BOT projects phase II based on option game," China Soft Science, no. 6, pp. 81-85, 2007 (Chinese).

[30] L. Gong, J. Guo, and G. X. Zhang, "Negotiation game model for infrastructure BOT project concession period," Statistics and Decision-Making, no. 4, pp. 153-155, 2008 (Chinese).

[31] Shaked. A and J. Sutton, "Natural oligopolies and international trade," in Monopolistic Competition and International Trade, $\mathrm{H}$. Kierszkowski, Ed., Oxford University Press, Oxford, UK, 1948.

[32] Q.-F. Cui, Z.-G. Wang, X.-H. Chen, and F.-H. Wen, "Sufficient conditions for non-Bazilevič functions," Abstract and Applied Analysis, vol. 2013, Article ID 154912, 4 pages, 2013.

[33] J. B. Song, W. Dang, and Y. Sun, "Flexible concession period decision-making models for infrastructure BOT project-multiple cases study on typical projects abroad," Civil Engineering Journal, no. 4, pp. 142-150, 2013 (Chinese). 


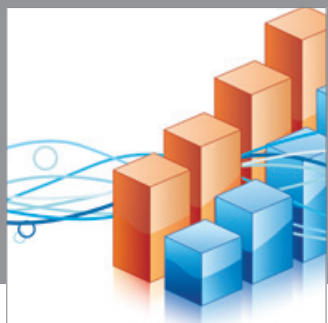

Advances in

Operations Research

mansans

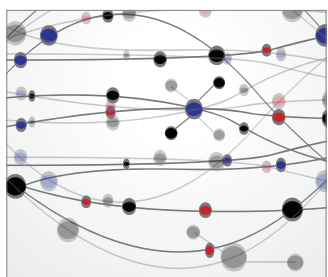

The Scientific World Journal
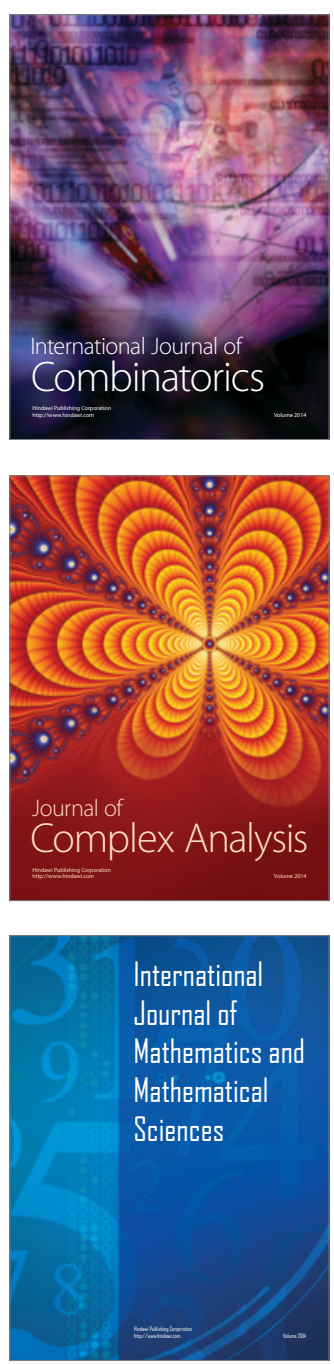
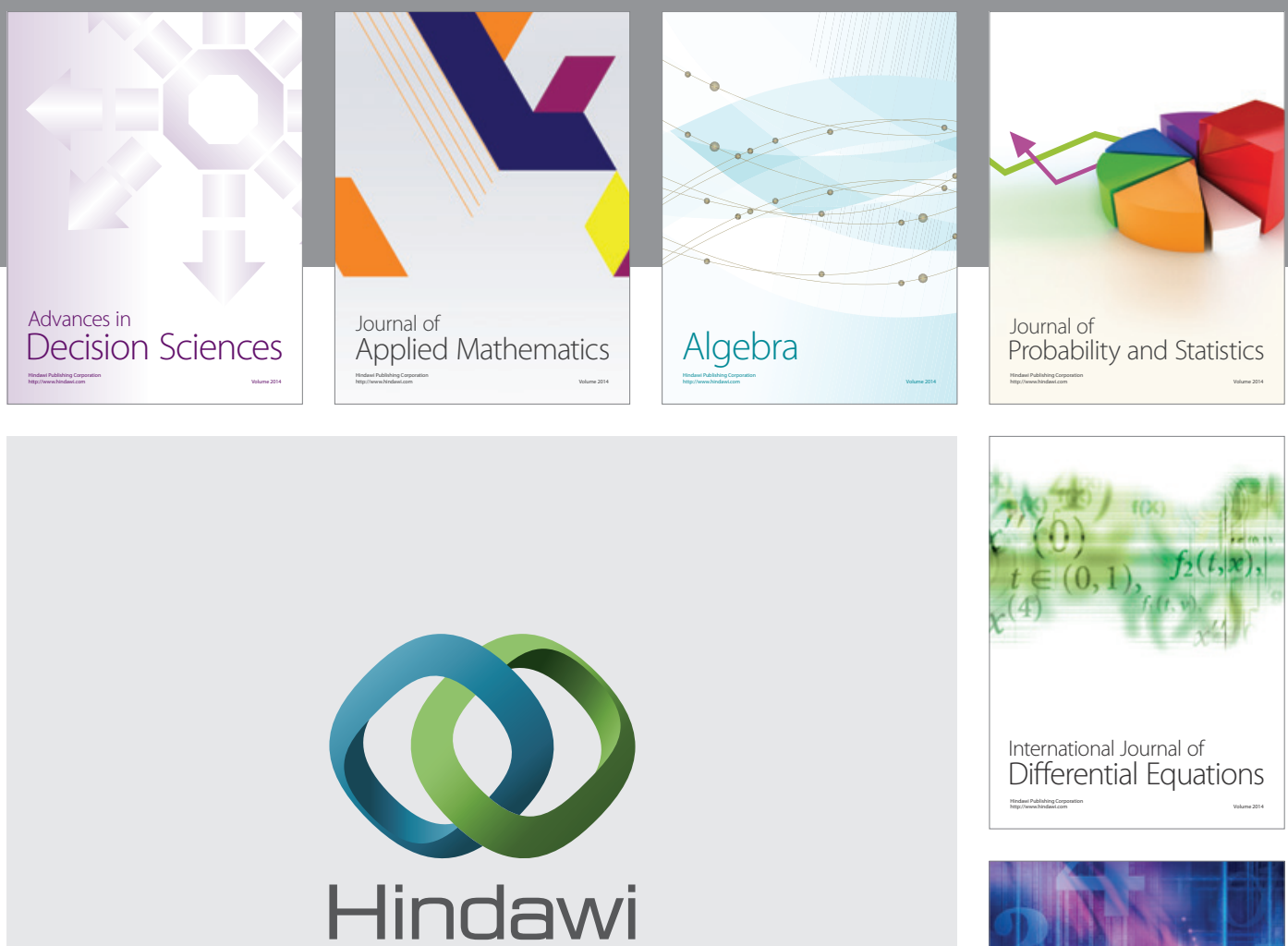

Submit your manuscripts at http://www.hindawi.com
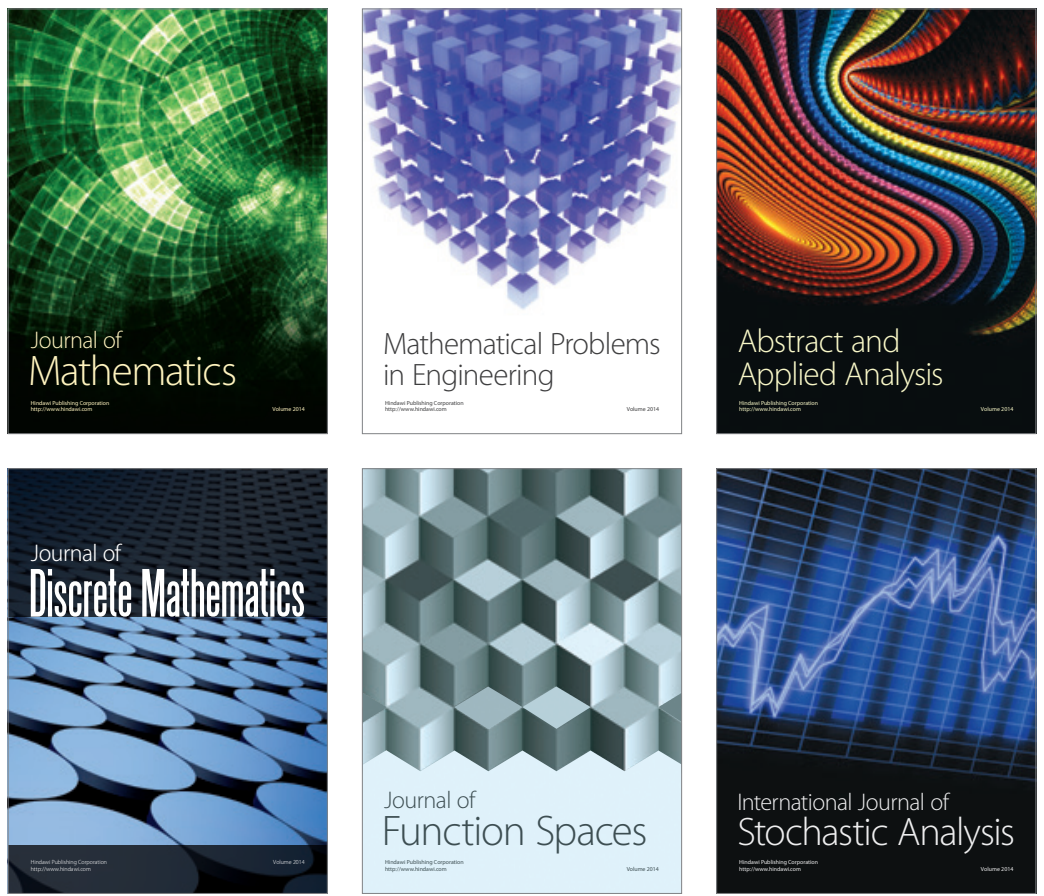

Journal of

Function Spaces

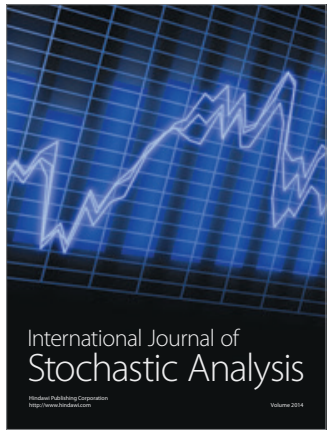

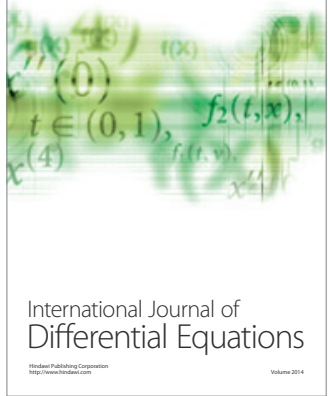
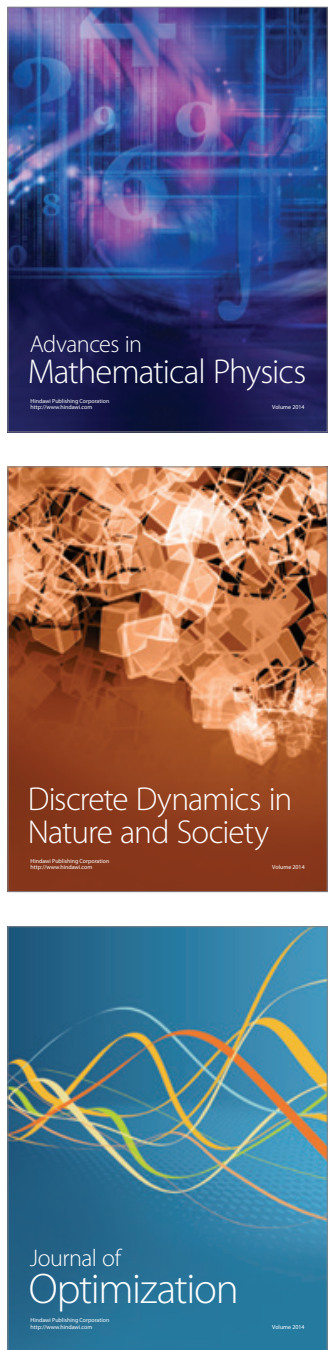